\title{
Study on Social Software Interface Subtracting Design Used by the Ageing Population-Taking Facebook as an Example
}

\author{
Ting-Yi Wu and Rain Chen
}

\begin{abstract}
Taiwan has become an ageing society that the ageing population is increasing. However the existing social software interface is designed for young people aged 25-34 so it is inconvenient for elderly people. There are a lot of researches related to the interface design for ageing people. However, most of these researches are related to either information ordering approach of the interface or size and ordering of images and texts. The objective of this study is to explore the use of subtracting design on social software by the ageing population. The object of study includes experimental group 17 ageing people aged 55 or above and control group 17 young people aged under 55. They operated the original Facebook interface (Interface A) and Facebook with interface of subtracting design (Interface B). This study has applied Paired-Samples $T$ test testing the 4 indexes, including operation time, number of errors, mental workload and subjective satisfaction. The result shows that except the mental workload in control group, others are significant differences for all 4 indexes. This shows that Interface $B$ is easier to operate than Interface A. Proper subtracting design of interface will help the ageing population using the social software, and effectively improve the using efficiency, subjective satisfaction, and reduce the level of mental workload.
\end{abstract}

Index Terms-Ageing population, interface design, social software, subtracting design.

\section{INTRODUCTION}

According to the statistics of Ministry of the Interior in 2018, the ageing population aged 65 in Taiwan has exceeded $14 \%$ and the country becomes the ageing society [1]. According to "2017 First Half Taiwan Internet Usage Survey", the Internet usage rate has reached $97 \%$. The Internet usage rate for people aged 50 or above is $66.9 \%$. Besides, the trend is moving upwards. The users aged 25-34 have the highest Internet usage rate [2]. In order to attract the young consumers, the software developers develop different functions and user interfaces, so that the operation of the interfaces becomes more complicated.

The function of interface is to guide the users getting the required information. The operation of the interface should be easy to learn and operate by the users, and avoid causing too much memory workload [3]. For the consideration of interface design, the unnecessary options should be reduced in order to make the interface simple and clear. The messages shown on interface should be short texts so that users can understand instantly [4].

As the age increases, the physiological function will gradually degenerate. The regression of faculty of memory, attention and cognitive ability will cause learning difficulties and obstacles [5]. The operation and demand cognition of the interface will be varied as the ages increase. Since the status of the physiological functions is different, the operation fluency and response to the messages for young population are better than ageing population [6]. The existing interface design has been focused for young population for which it causes the ageing people difficult to use and recognize. In order to meet the requirement of different users, developers should develop interfaces for the corresponding users.

According to the survey, the most common behaviors on Internet include "connecting to online communication software 80.6\%", "connecting to network community 74.1\%", and "browsing web sites 53.6\%" [7]. The motivations of ageing population using mobile include emotional connection, and maintaining and expanding interpersonal relationships [8]. According to the survey from Research, Development and Evaluation Commission, it is found that interaction with relatives and friends has certain importance to ageing people [9]. The social software could increase the interactive relationship between the relatives and friends. Real time interaction could lower the psychological loneliness [10]. However, certain assistance to ageing people on Internet operation is required. Due to the regression of physiological functions and additional functions on interfaces, it is not easy for ageing people to operate and recognize. If there is not instant assistance, the operation may be interrupted or stopped. Unfortunately, in the current community software, there is no consideration about the emotions and influence of the ageing users.

The relevant survey shows that the ageing Facebook users aged 55 or above is increasing and becomes the second biggest user group [11]. This study has taken Facebook as example for subtracting design. Only the interactive functions such as online chatting and communication are left. The purpose is to explore whether there is significant difference for the ageing population operating the social software after the subtracting design has been applied.

\section{METHOD}

Manuscript received September 14, 2018; revised December 8, 2018.

Ting-Yi $\mathrm{Wu}$ and Rain Chen are with Department of Visual Communication Design, Southern Taiwan University of Science and Technology, Tainan, Taiwan R.O.C. (e-mail: ma6j0102@stust.edu.tw, ocean@stust.edu.tw).

\section{A. Subjects}

The object of study are ageing people aged 55 or above and young people aged under 55 . The voluntary subjects 
have been found from the care activity center. The information of the subjects, including gender, age, academic level, and Internet usage experience have been collected by the questionnaires. There have been 17 subjects in experimental group, and $18 \%$ of them are male and $82 \%$ of them are female. For the academic level, $65 \%$ of them are high school or below, and $35 \%$ are university or above. 17 subjects in control group, and $41 \%$ of them are male and $59 \%$ of them are female. For the academic level, $18 \%$ of them are high school or below, and $82 \%$ are university or above.

\section{B. Samples}

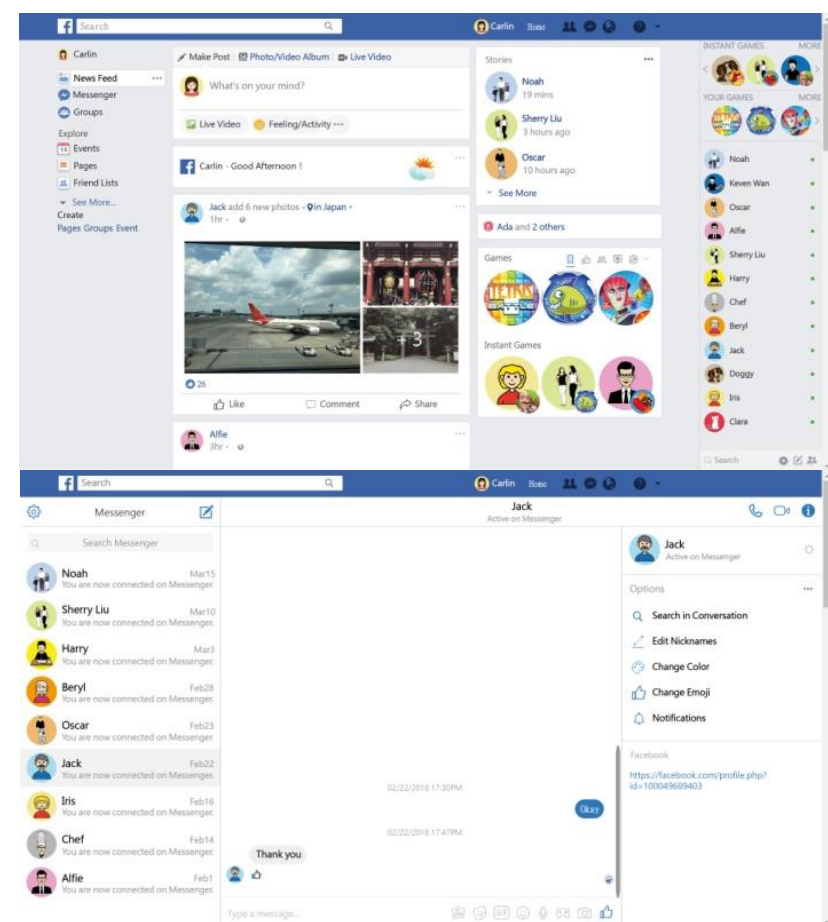

Fig. 1. Original Facebook interface (interface A).

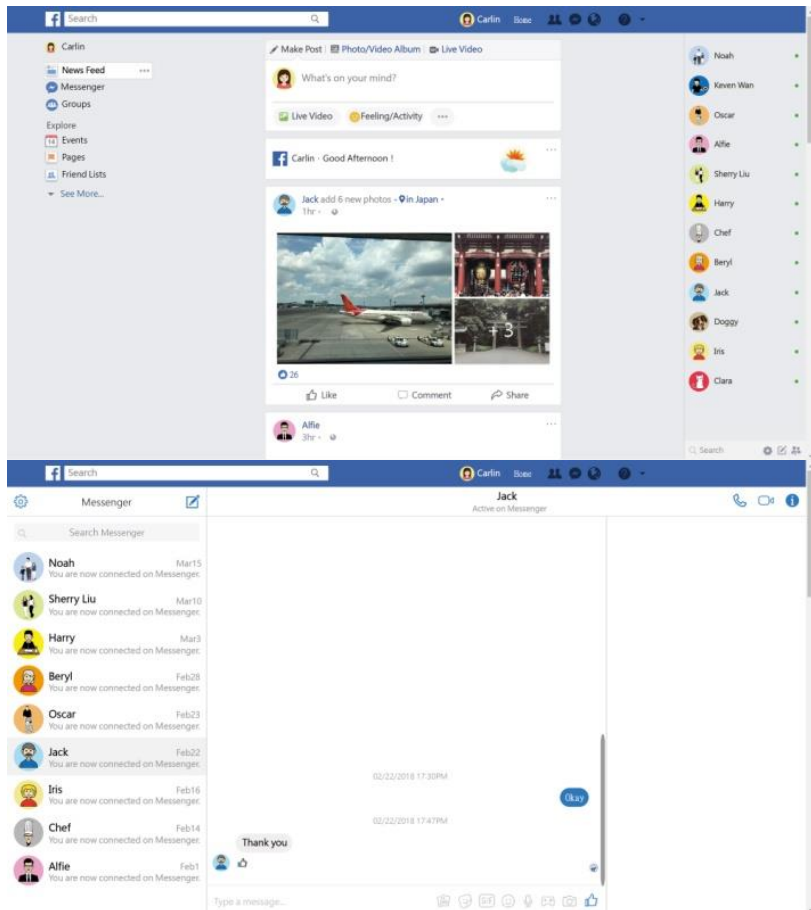

Fig. 2. Facebook interface with subtracting design (Interface B).

The test sample includes the original Facebook interface (hereafter the Interface A), and the Facebook interface after applying subtracting design according to the literatures for which only online chatting and communication has been remained (hereafter the Interface $\mathrm{B}$ ). The operating functions and the positions of the functions of Interface A (as shown in Fig. 1) and Interface B (as shown in Fig. 2) are the same. After the questionnaire survey, this study explained the functions of the Facebook interface to the subjects. Then they operated Interface A or Interface B in random. The task was to check the pictures in dynamic news. After that, they returned to home page and sent real time message. After the task, they filled in the NASA-Task Load Index (NASA) and System Usability Scale (SUS). The Process flow diagram as Fig. 3.

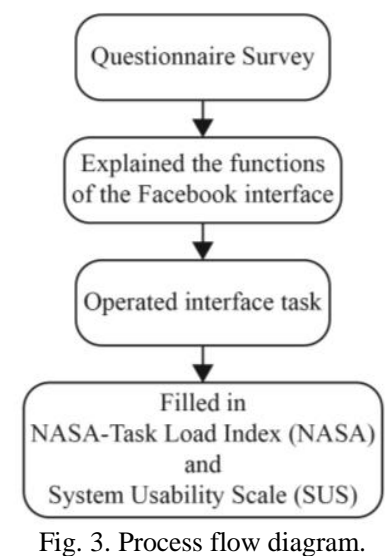

\section{Tools}

The hardware includes a 14" laptop and mouse. In the process, the operation time, number of mouse clicks, and mouse moving track of the subjects has been recorded by screen recording software for further statistics in the future.

The data from experiment and questionnaires have been calculated by Excel and tested by SPSS software. This study has tested whether there are significant differences for the four indexes, including operation time, number of errors, mental workload and subjective satisfaction by PairedSamples T test.

\section{Scale}

This study has applied NASA, and applied Likert 7 Scale for measurement. The mental workload level of the subjects after operating Interface A or Interface B was tested by the six indexes (including mental workload, physiological loading, time loading, vigor spent, performance, frustration).

This study has applied SUS. The Likert 5 Scale has been used for measurement. SUS is applicable for small sample test with only 12 subjects. Through the 10 positive and negative questions, the subjective satisfaction of subjects operating Interface A or Interface B has been evaluated.

\section{RESULT}

The data collected from the experiment and questionnaires have been analyzed by SPSS. The PairedSamples $\mathrm{T}$ test has been applied for subjects operating Interface A or Interface B. The result is shown in Table I and Table II. Operating time is the time taken completing the task (the unit is second). Number of errors it the number 
of errors for the subjects operating the interface. The data analyzed by NASA and SUS was received from the scale written by the subjects.

\begin{tabular}{|c|c|c|c|c|}
\hline Index & Mean & $\begin{array}{l}\text { Standard } \\
\text { Deviation }\end{array}$ & $\mathrm{T}$ value & $\mathrm{P}$ value \\
\hline $\begin{array}{l}\text { Operating } \\
\text { time (A) }\end{array}$ & 135.353 & 70.968 & 4.822 & 0.000 \\
\hline $\begin{array}{l}\text { Operating } \\
\text { time (B) }\end{array}$ & 83.471 & 59.977 & & \\
\hline $\begin{array}{l}\text { Number of } \\
\text { errors (A) }\end{array}$ & 8.647 & 16.128 & 2.405 & 0.029 \\
\hline $\begin{array}{l}\text { Number of } \\
\text { errors (B) }\end{array}$ & 4.588 & 9.644 & & \\
\hline NASA (A) & 3.369 & 1.697 & 3.346 & 0.004 \\
\hline NASA (B) & 2.504 & 1.125 & & \\
\hline SUS (A) & 71.177 & 24.877 & -3.670 & 0.002 \\
\hline SUS (B) & 78.382 & 23.683 & & \\
\hline
\end{tabular}

\section{A. Operating Time}

According to Table I, the $\mathrm{t}$ value of Paired-Samples T test for Interface $A$ and Interface $B$ is 4.82. The two-tailed significant $P$ value $=0.00<0.05$. It means that there has been significant difference on time for operating Interface A and Interface B in experimental group. According to Table I, the operating time for Interface $\mathrm{A}$ in experimental group have been $\mathrm{M}=135.353$ and $\mathrm{SD}=70.968$. The operating time for Interface $\mathrm{B}$ in experimental group have been $\mathrm{M}=83.471$ and $\mathrm{SD}=59.977$. It is obvious that operating time for Interface $\mathrm{B}$ is shorter than Interface A. This shows that Interface B is easier for operation.

\section{B. Number of Errors}

According to Table I, the $t$ value of Paired-Samples T test for Interface A and Interface B is 2.405. The two-tailed significant $\mathrm{P}$ value $=0.029<0.05$. It means that there has been significant difference on number of errors for Interface A and Interface B in experimental group. According to Table I, the number of errors for Interface A in experimental group have been $\mathrm{M}=8.647$ and $\mathrm{SD}=16.128$. The number of errors for Interface B in experimental group have been $\mathrm{M}=4.588$ and $\mathrm{SD}=9.644$. It is obvious that number of errors for Interface B is less than Interface A. This shows that Interface $\mathrm{B}$ is easier for operation.

\section{NASA}

According to Table $\mathrm{I}$, the $\mathrm{t}$ value of Paired-Samples $\mathrm{T}$ test for Interface A and Interface B is 3.346. The two-tailed significant $\mathrm{P}$ value $=0.004<0.05$. It means that there has been significant difference on mental loading for Interface A and Interface B in experimental group. According to Table I, the mental loading for Interface A in experimental group have been $\mathrm{M}=3.369$ and $\mathrm{SD}=1.697$. The mental loading for Interface $\mathrm{B}$ in experimental group have been $\mathrm{M}=2.504$ and $\mathrm{SD}=1.125$. It is obvious that mental loading for Interface $\mathrm{B}$ is lower than Interface A. This shows that it is less laborious operating Interface $B$.

\section{SUS}

TABLE II: TEST RESUlt OF CONTROL GROUP INTERFACE A AND

\begin{tabular}{lcccc}
\hline \multicolumn{1}{c}{ Index } & Mean & $\begin{array}{c}\text { Standard } \\
\text { Deviation }\end{array}$ & T value & P value \\
\hline $\begin{array}{l}\text { Operating } \\
\text { time (A) }\end{array}$ & 44.529 & 25.606 & 3.302 & 0.005 \\
$\begin{array}{l}\text { Operating } \\
\text { time (B) }\end{array}$ & 25.471 & 11.159 & & \\
Number of & 2.765 & 3.849 & 2.255 & 0.039 \\
errors (A) & & & & \\
Number of & 0.765 & 1.033 & & \\
errors (B) & & & & \\
NASA (A) & 3.065 & 1.478 & 1.314 & 0.207 \\
NASA (B) & 2.650 & 0.922 & & \\
SUS (A) & 68.235 & 17.979 & -3.135 & 0.006 \\
SUS (B) & 80.735 & 14.517 & & \\
\hline
\end{tabular}

According to Table I, the $t$ value of Paired-Samples T test for Interface A and Interface B is -3.67. The two-tailed significant $\mathrm{P}$ value $=0.002<0.05$. It means that there has been significant difference on subjective satisfaction for Interface $\mathrm{A}$ and Interface $\mathrm{B}$ in experimental group. According to Table I, the subjective satisfaction for Interface $\mathrm{A}$ in experimental group have been $\mathrm{M}=71.177$ and $\mathrm{SD}=24.877$. The subjective satisfaction for Interface $\mathrm{B}$ in experimental group have been $\mathrm{M}=78.382$ and $\mathrm{SD}=23.683$. It is obvious that subjective satisfaction for Interface B is higher than Interface A. This shows that Interface B is easier for operation.

\section{E. Operating Time}

According to Table II, the $\mathrm{t}$ value of Paired-Samples $\mathrm{T}$ test for Interface A and Interface B is 3.302. The two-tailed significant $\mathrm{P}$ value $=0.005<0.05$. It means that there has been significant difference on time for operating Interface $A$ and Interface B in control group. According to Table II, the operating time for Interface A in control group have been $\mathrm{M}=44.529$ and $\mathrm{SD}=25.606$. The operating time for Interface $\mathrm{B}$ in control group have been $\mathrm{M}=25.471$ and $\mathrm{SD}=11.159$. It is obvious that operating time for Interface B is shorter than Interface A. This shows that Interface $\mathrm{B}$ is easier for operation.

\section{F. Number of Errors}

According to Table II, the $t$ value of Paired-Samples $\mathrm{T}$ test for Interface A and Interface B is 2.255. The two-tailed significant $\mathrm{P}$ value $=0.039<0.05$. It means that there has been significant difference on number of errors for Interface A and Interface B in control group. According to Table II, the number of errors for Interface A in control group have been $\mathrm{M}=2.765$ and $\mathrm{SD}=3.849$. The number of errors for Interface $\mathrm{B}$ in control group have been $\mathrm{M}=0.765$ and $\mathrm{SD}=1.033$. It is obvious that number of errors for Interface $\mathrm{B}$ is less than Interface A. This shows that Interface B is easier for operation.

\section{G. NASA}

According to Table II, the $\mathrm{t}$ value of Paired-Samples $\mathrm{T}$ 
test for Interface A and Interface B is 1.314. The two-tailed significant $\mathrm{P}$ value $=0.207>0.05$. It means that there hasn't been significant difference on mental loading for Interface A and Interface B in control group.

\section{H. SUS}

According to Table II, the $t$ value of Paired-Samples $\mathrm{T}$ test for Interface A and Interface B is -3.135 . The two-tailed significant $\mathrm{P}$ value $=0.006<0.05$. It means that there has been significant difference on subjective satisfaction for Interface $\mathrm{A}$ and Interface $\mathrm{B}$ in control group. According to Table II, the subjective satisfaction for Interface A in control group have been $\mathrm{M}=68.235$ and $\mathrm{SD}=17.979$. The subjective satisfaction for Interface B in control group have been $\mathrm{M}=80.735$ and $\mathrm{SD}=14.517$. It is obvious that subjective satisfaction for Interface B is higher than Interface A. This shows that Interface B is easier for operation.

\section{DISCUSSION AND CONCLUSION}

The object of study includes 17 ageing people aged 55 or above and 17 young people aged under 55. They operated original Facebook interface (Interface A) and Facebook with interface of subtracting design (Interface B). This study has applied Paired-Samples $\mathrm{T}$ test testing the 4 indexes, including operation time, number of errors, mental workload and subjective satisfaction.

The result in experimental group shows that the 4 indexes of Facebook interface (Interface B) with subtracting design are better than that of original Facebook interface (Interface A). For ageing population, it is obvious that Interface B is easier for operation.

The result in control group shows that except the mental workload other indexes of Facebook interface (Interface B) with subtracting design are better than that of original Facebook interface (Interface A). For young population, Interface $\mathrm{B}$ is also easy for operation.

To properly reduce the information could help to improve the operating performance of ageing population and effectively reduce the mental loading. Since there are only a few samples in this study, and there may be learning effect in the experimental process, which may cause Interface B better than Interface A. Besides, only one medium has been applied for the test. This may cause error in experiment. When researchers study the relevant topics in the future, it is suggested to improve the different media and number of samples.

\section{ACKNOWLEDGMENT}

This work was partially supported by the Ministry of Science and Technology, Taiwan, under the Grant No. MOST 106-2221-E-218 -026 -MY2.

\section{REFERENCES}

[1] MOI. (2018). Ministry of the Interior Statistical Review. [Online] Available:

https://www.moi.gov.tw/chi/chi_site/stat/news_detail.aspx?sn=13742

[2] Insight Xplorer. (2017). The first half of 2017 Taiwan Internet Usage Survey. [Online]. Available: http://www.ixresearch.com/news/news_09_12_17

[3] K. Cox and D. Walker, User Interface Design, 2nd ed. New York: Prentice Hall, 1993.

[4] D. Hawthorn, "Possible implications of aging for interface designers," Interacting with Computers, vol. 12, no. 5, pp. 507-528, 2000.

[5] C. F. Lee, "Approaches to product design for the elderly," Journal of Design. Interacting with Computers, vol. 11, no. 3, pp. 65-80, 2006.

[6] N. T. Wang and C. M. Cheng, "Usability of paging on smartphones for the middle age and elderly," Journal of Gerontechnology and service Management, vol. 3, no. 1, pp. 5-14, 2015.

[7] Taiwan Network Information Center. (2016). 2015 Taiwan Wireless Cable Using Survey. [Online]. Available: http://www.seminar2016.twnic.tw/mt/330-1510-03.pdf

[8] W. W. Day, "Digital autonomy: Examining the digital content policy in Taiwan," The Journal of Information Society, vol. 10, pp. 235-264 2006.

[9] Research, Development and Evaluation Commission. (2014). 2013 Digital Opportunity Survey of People Aged above 50. [Online]. Available: https://srda.sinica.edu.tw/datasearch_detail.php?id=312

[10] N. Alm, P. Gergor, and A. F. Newell, "Older people and information technology are ideal partners," in Proc. the International Conference for Universal Design, Japan, 2002, pp. 754-760.

[11] eMarketer. (2018). Facebook Losing Younger Users. [Online]. Available: https://www.emarketer.com/content/facebook-losingyounger-users-at-even-faster-pace

Ting-Yi Wu received the bachelor degree in Department of Creative Product Design from Southern Taiwan University of Science and Technology (STUST) in Taiwan. Now, she is a student in master program in visual communication design from Southern Taiwan University of Science and Technology (STUST). Her area of expertise is the product design and design research.

Rain Chen received the MS/ PhD degree in industrial design from National Cheng Kung University (NCKU) in Taiwan. He had been patent examiner in Intellectual Property Office of Taiwan (TIPO). He got patent attorney qualifications in 2009. Now, he is a professor in Southern Taiwan University of Science and Technology (STUST). His area of expertise is the product design, patent management, intellectual property rights, and design management. 